\title{
1. Mapping Early Minimalism
}

\section{Keith Potter}

When writing the New Grove entry on minimalism for this dictionary's 2001 edition, ${ }^{1}$ I thought it best to restrict myself to the narrower definitions and interpretations of the term 'minimalism' stemming from the narrative set in motion by the ideas and work of La Monte Young, Terry Riley, Steve Reich and Philip Glass in the 1960s - even though to do so was to allow these figures a hegemony in this area that some would find unacceptable. And as the author of Four Musical Minimalists, published the year before, I confined any broader excursions into this territory along purely musichistorical lines to two matters. Some investigation was attempted of the first uses of the description 'minimal' in a musical context, by Michael Nyman and Tom Johnson, as applied, respectively, to compositions by Henning Christiansen (1932-2008), the Danish composer and member of Fluxus, and Alvin Lucier (b. 1930), the American pioneer in exploring acoustic and psycho-acoustic phenomena as the basis for making music: two composers who could well provide alternative starting points for 'mapping minimalist music'. And the emergence was noted of musical minimalism out of what Nyman (again), following John Cage, called 'experimental music'; which meant, basically, pursuing another USA-based story in which Cage himself is the major

\footnotetext{
${ }^{1}$ See Keith Potter, 'Minimalism', in Stanley Sadie (ed.), The New Grove Dictionary of Music and Musicians, 16 (London, 2001), pp. 716-18.
} 
player. For the rest, my introduction to that book concerned minimalist art, and a mixture of cultural history and cultural theory that seemed appropriate to the task. ${ }^{2}$

If I once more focus on the four 'usual suspects' in the present chapter, this is for four reasons. ${ }^{3}$ First, issues around defining minimalism have been addressed by all three editors at the start of this book. Second, really 'broadbrush' approaches to charting what might reasonably be deemed 'minimalist territory' raise questions that cannot properly be answered in so short a space: a further deferral is, then, proposed for any future work on this. To give a single example out of many that are possible, take Robert Fink’s tale of a 25-day 'performance' in 1957 by the much-venerated Japanese violin pedagogue Shinichi Suzuki. '[Placing] the bow on a string, then [producing] beautiful tone with the well-balanced bow', he quotes Suzuki as saying, 'I carefully played a stroke at a time after checking the balance of the bow each time. I did this exercise 100,000 times (it took me about 25 days). People', Suzuki reported, 'recognized the leaping progress in the beauty and clarity of my tone in those 25 days.' If, Fink goes on, such a demonstration of the Suzuki method as repetitive Soto practice, translated into repetitive musical process, had been publicly performed in 1957 'in a lower Manhattan loft space, [Suzuki] would now be hailed as a pioneer of

\footnotetext{
${ }^{2}$ See Keith Potter, Four Musical Minimalists: La Monte Young, Terry Riley, Steve Reich, Philip Glass (Cambridge, 2000), pp.1-20.

${ }^{3}$ Some later parts of this chapter present revised versions of material that originally appeared in my keynote lectures for the Society for Minimalist Music: '1976 and All That:minimalism and post-minimalism, analysis and listening strategies’, First International Conference on Minimalist Music(31 August-2 September 2007), Bangor University, North Wales; at <http://www.musicminimalism.org> [accessed 3 October 2011]; and 'Conceiving Conceptualism, Perceiving the Actual: some thoughts on La Monte Young's text compositions', Conference on La Monte Young’s Compositions 1960 (29 May 2010), University of Huddersfield, UK.
} 
"hypnotic" musical minimalism, having beaten La Monte Young to the composition of arabic numeral (any integer) by a full three years'. ${ }^{4}$

Third, some, at least, of the many 'alternative histories' of early musical minimalism in First- and Second-World cultures are tackled by other authors in this volume: whether moving outside the USA-based purview (Maarten Beirens on European minimalism, for instance) or staying within it (Dean Suzuki's coverage of musical minimalism in a performing-arts context, for instance, or Jonathan Bernard's investigation of the convergences arising when minimalism and popular music are jointly examined). Fourth, and lastly, the job of exhuming, making available and assessing the outputs of those individual composers and improvisers who might lay claim to as yet inadequately recognized significance in the story of musical minimalism is, at last, now being done by specialists who have made it their business to gain the particular kinds of access necessary to tell such stories reliably and as comprehensively as possible.

Such scholarship, of course, is often American-based and often requires extending the search outside the area of purely musical endeavour. It includes recent and ongoing efforts on behalf of such figures as, from the USA, Terry Jennings (by Brett Boutwell and Christopher Hobbs), Dennis Johnson (by Kyle Gann), Meredith Monk (a better-known composer-performer, but one on whom still very little scholarship has been done) and Phill Niblock (by a number of writers, including myself); or, from elsewhere, the Belgian Karel Goeyvaerts (by Mark Delaere and

\footnotetext{
${ }^{4}$ Robert Fink, Repeating Ourselves: American minimal music as cultural practice (Berkeley, 2005), pp. 232-3.
} 
Maarten Beirens), the Russians Nikolai Korndorf, Vladimir Martynov, Sergei Zagny and (in particular, in the case of her own present research) Alexander Knaifel (by Tara Wilson), and the Lithuanian Bronius Kutavicius (by Antonas Kucinskas), to say nothing of the burgeoning scholarship on performance art, the early history of tape and other technologies and so on. All these will surely, in due course, not only yield a plethora of new information, but also form the basis for future assessments of musical minimalism much broader than those in the present chapter - even, indeed, than in this book as a whole. ${ }^{5}$ I look forward to that time, since much good work is now being done by a generation of scholars for whom such creative activity is a serious topic for scholarly endeavour and not, as it as been for so many of my own generation, the subject of derision.

\section{Two Alternative Minimalisms?}

To return to 2001, however. When writing that Grove entry, I was nevertheless at pains to stress that there seemed to be at least two rather contradictory views of musical minimalism in circulation; and I thought that I had at least implied - though it seems not always successfully so, to judge from some of the feedback that I have had

\footnotetext{
${ }^{5}$ In addition to several other chapters in this volume, see Kyle Gann, 'Reconstructing November', American Music, 28/4 (2010): pp. 481-91; this details the process of transcribing and completing the composition for solo piano of that title - dating from 1959 and reputed to have originally been six hours long - by Dennis Johnson, a student friend of La Monte Young’s. And both the several papers on Phill Niblock given at the Second International Conference on Minimalist Music(2-6 September 2009), University of Missouri-Kansas City, USA (at which Gann also gave a paper on Johnson's November, and Sarah Cahill and he played a realization of the work), and the several articles in German, including two by contributors to the present volume, on Niblock in MusikTexte, 132 (2012).
} 
- that some of the problems there appeared to be in defining and understanding what minimalism in music had been, and could be, probably arose from confusing those two contradictory views. It might, accordingly, be helpful to begin by attempting to identify these two approaches as clearly as possible. And then to take look, in a chapter confined to the earlier manifestations of musical minimalism, at the first of them, including some of the ways in which it already gave clues as to how the second approach later came about. I aim to show that, far from generating two neatly distinguishable maps, which might be thought to be the desired outcome, the position is, in practice, rather messier.

So what are these two opposing views? First, there is the avowedly radical one, conjuring up the image of a music of drastic cheese-paring of material means, of opposition in the socio-cultural sphere (whether it concerns a riposte to the social or political establishment, a challenge to the artist's professional status or an attempt to denigrate immediately prior art forms), and of perceptual challenge to its (necessarily modest-sized) audiences. Such a radical minimalism would be firmly characterized as a cultural Other to any kind of 'mainstream' practice.

Second, there is the apparently conservative view, folding itself back fairly comfortably into any notion of a surviving late-twentieth-century 'mainstream' that has survived the ravages of modernism. Such a minimalism is now frequently read as the sensible, and in retrospect inevitable, return to the basic building blocks of music that significant areas of Western composition, particularly in the third quarter of the twentieth century, had rejected. As I wrote in 2001, such a minimalism is widely seen 
the major antidote to Modernism, as a reaction against both the serialism of the American Milton Babbitt and the European composers Pierre Boulez and Karlheinz Stockhausen, and against the indeterminacy of John Cage. This minimalism openly seeks greater accessibility. It is tonal or modal where Modernism is atonal, rhythmically regular and continuous where Modernism is aperiodic and fragmented, structurally and texturally simple where Modernism is complex. First flourishing to popular acclaim in the USA, it was typified in the 1980s and 90s by the music of ... Glass ... probably the most commercially successfulcomposer of the later 20th century to work predominantly within the concert halls and opera houses of the 'cultivated tradition'. 6

\section{Minimalism as Modemism?}

The first, radical, view surely emerges in part out of minimalist music's contacts with Minimalist visual art, whatever the difficulties experienced in comparing two quite different media, and however much the composers of this radical music might register protests about the usefulness of the links with the artists themselves, their ideas and practice that are asserted on their behalf by others. The so-called Black paintings of Frank Stella, first exhibited in 1959, are usually credited with being the first artworks of Minimalism. Minimalist painting thus predates Minimalist sculpture; reminding us that this fact tends to be forgotten, Edward Strickland argues that the importance of Minimalist painting has been underestimated in the literature. ${ }^{7}$ It seems, nevertheless, to be the challenge thrown down by the 'new three-dimensional work' of the sculptor (and critic) Donald Judd, among several others, to the concept, practice and

\footnotetext{
${ }^{6}$ Potter, 'Minimalism', in The New Grove, p. 716.

${ }^{7}$ See Edward Strickland, Minimalism: origins (Bloomington and Indianapolis, 1993).
} 
perception of painting on rectangular flat surfaces that most firmly projected Minimalism to the forefront of artistic developments in the 1960s. Most of these early Minimalist artists, including Sol Le Witt, Robert Morris and Richard Serra, and many of the early minimalist composers, had New York as their central professional base; which, of course, suggests that links between them would be natural and likely to be nurtured, if not inevitable. Minimalist sculptures proclaim not only a firm rejection of representational painting but also, like Minimalist painting, a rejection of the highly individualized and gestural outcomes of another American art movement, Abstract Expressionism: dominant in the 1950s and practised by, for example, Willem de Kooning and Jackson Pollock.

Links between the artists and the musicians, and between the art and the music here, can of course be biographical ones. For all the protestations that Reich, for instance, has made concerning the overrating of the extent and significance of his connections to figures such as Le Witt and Serra, the evidence seems undeniable. One example each must suffice here for Reich and Glass.

Steve Reich (b. 1936) was close to Le Witt in the years 1967-70, and the artist bought the original score of Four Organs so that the hard-up composer could buy glockenspiels for Drumming. Le Witt may also have purchased some sections of Drumming's manuscript as well, though the only evidence that I have uncovered so far among Reich's papers (now acquired by the Paul Sacher Stiftung in Basel) is a page torn out of one of the composer's sketchbooks. Labelled 'first version of reductions from Drumming' ('reductions' signalling the process of gradually reducing the complete Basic Unit to a single note), this was originally dated 15 December 
1970. On 7 February 1971, Reich added 'for Sol from Steve Sunday 2/7/71', photocopied the page and stuck the photocopy in his sketchbook in place of the original. Though this could have been bought by Le Witt, the original itself could also have been given as a present to him; either way, the artist would have quite possibly placed a financial as well as a sentimental value on it, just as if he would have if a fellow visual artist had given him a sketch of some kind.

Philip Glass (b. 1937) first met Serra - and Serra's then partner, the painter and sculptor, Nancy Graves - in Paris in the mid-1960s, when Glass was studying composition with Nadia Boulanger, and Serra and Graves were both on travelling fellowships to Europe. Back in New York soon after this, Glass says that Graves helped him in a variety of ways, including the design of posters for his concerts. Serra offered even greater support, including the employment of Glass for a period as a fulltime studio assistant. In 1969, the composer - together with the artist Chuck Close (creator of the iconic portrait of Glass made in the same year), the performance artist Spalding Gray, Dicky Landry (a member of the composer's ensemble) and others helped Serra to 'choreograph' the mounting of his 'second lead series' of sculptures at Leo Castelli's Warehouse. This was entitled 1-1-1, 2-1-1, 2-1-2, reminiscent of Glass’s own work, $1+1$ (1968). ${ }^{8}$

Such links between Minimalist art and minimalist music can also be conceptual: which can mean a number of things, but often boils down to some measure of agreement concerning the avoidance of 'comment, representation, or

\footnotetext{
${ }^{8}$ Richard Serra, 'Rigging’ (1980), Writings, Interviews (Chicago and London, 1994), p. 97.
} 
reference' 9 and '[shifting] the attention away from he and she and you and me outward toward it'. ${ }^{10}$ Or they can be technical: which can mean selecting material that tests the limits of how 'eliminating transformative labor'11 can operate in transforming an idea into a work of art or music. Or they can be perceptual: which can mean being interested in the nature and structure of the material being used in order to:

recover the sensation of life ... to make us feel things, to make the stone stony. The end of art is to give a sensation of the object as seen, not as recognised. The technique of art is to make things 'unfamiliar', to make forms obscure, so as to increase the difficulty and duration of Perception. ${ }^{12}$

La Monte Young's 'getting inside sound' is another way of putting this. Or such links can be receptional: which can mean accepting all the above as a critique of contemporary culture, not a mere means of entertainment.

So what musical works are closest, in whatever way, to this radical art? For many, still today, the 1960s minimalist compositions of Reich and Glass are what first comes to mind here, and remain, aside from Riley's In $C$ (1964), by some way the best-known. In $C$ itself - 'unquestionably the founding work of minimalism in

\footnotetext{
${ }^{9}$ Frances Colpitt, Minimal Art: the critical perspective (Ann Arbor, 1990), p. 3.

10 Steve Reich, 'Music as a Gradual Process’ (1968), in Writings on Music 1965-2000, Paul Hillier (ed.) (Oxford, 2002), p. 36.

${ }^{11}$ Kenneth Baker, Minimalism: art of circumstance (New York, 1988), p. 43.

12 Viktor Schklovsky, quoted in David Lodge, 'Modernism, Antimodernism and Postmodernism', in Working with Structuralism: essays and reviews on nineteenth- and twentieth-century literature (London, 1981), p. 9.
} 
musical composition' and 'a signature piece in the American counterculture'13 - will surely retain its position, as our musical histories are rewritten, as one of the seminal compositions of the mid-twentieth century, and it was a crucial influence on many others composers, Reich included. But its relationship to the more extreme and critique-based ideas raised above is sufficiently questionable to permit an intelligent commentator such as William Brooks to suggest that the work's 'surface features ... combine to signify not variability but certainty. Such a work is not only a massproduceable commodity in its totality; its very constituents are commodities. Rather than opposing fashion and disposability, In $C$ affirms them; it required an audience not of specialists but of consumers'. ${ }^{14}$

With Reich's tape compositions, It's Gonna Rain (1965) and Come Out (1966), and his first instrumental works to borrow the tape-derived technique of phasing, Piano Phase and Violin Phase (both 1967), we seem on firmer ground in any attempt to develop a theory of musical minimalism as offering a critique parallel to the challenge thrown down by Minimalist sculpture. The same can be said of Glass's first instrumental compositions to use additive process, Two Pages and Music in Similar Motion (both 1969), especially if you are thinking of music of a comparable quality and of a comparable structural rigour to that of Reich. We might also include Glass’s earlier, superficially similar works Strung Out for amplified violin (1967) and Gradus for soprano saxophone (1968), which likewise use repetitive but in this case

\footnotetext{
13 Robert Carl, Terry Riley’s In C (New York, 2009): dustsheet; and David Bernstein, quoted on p. 104, respectively.

14 William Brooks, 'The Americas, 1945-70', Robert P. Morgan (ed.), Modern Times: from World War I to the present (Basingstoke, 1993), pp. 343-4.
} 
unsystematic procedures; these can be interpreted as earlier consequences, still interesting if less successful, of Reich's already established example. And we might add Glass’s Play for soprano saxophone (1965) and his First String Quartet (1966); though with the former, for which no score or recording is presently available, we have only the word of the composer and just one or two of his contemporaneous colleagues that the work was identifiably minimalist at all. These - plus, especially, Reich’s Pendulum Music (1968), the conceptual and theatrical circumstances of which derive directly from the composer's installation work with the artist William T. Wiley - are the compositions that many still think of as the musical equivalents of Judd's or Morris's boxes, Le Witt's modular cubes and Serra's steel plates. ${ }^{15}$

It is good to be able to report that some very interesting scholarship is ongoing on such matters. To give just two examples: David Chapman is researching events that took place at New York's Park Place Gallery in March 1967 and at the Filmmakers’ Cinématheque in May 1968: the locations, respectively, of the premiere performances of what eventually became Reich's Piano Phase (the Park Place concerts offered 'Four Pianos', an earlier version) and of Glass’s 1968 compositions, Piece in the Shape of a Square for two flutes and How Now, in its original solo piano form (it later became a work for the then emerging Philip Glass Ensemble).

\footnotetext{
15 For more information on the earliest minimalist compositions of Reich and Glass (including their connections to minimalist artists), see Potter, Four Musical Minimalists, pp. 164-94 and pp. 265-303, respectively. For a recent edition of five of Glass's scores of this period, previously unavailable in reliable versions with adequate instructions, see Keith Potter (ed.), Philip Glass: first classics (New York and London, 2010). For new analytical approaches to this repertoire, see Keith Potter, Geraint A. Wiggins and Marcus T. Pearce, 'Towards Greater Objectivity in Music Theory: information-dynamic analysis of minimalist music', Musicae Scientiae, 11/2 (2007): pp. 295-324.
} 
Chapman's areas of interest include spatial audio effects as well as a re-evaluation of the roles of Jon Gibson and Art Murphy in the developing aesthetics of musical minimalism. ${ }^{16}$

Kerry O’Brien, meanwhile, is attempting a closer look than anyone else has yet managed at the role of technology in 1960s musical minimalism, including the work not only of Reich but also of Young and others. One concern here is 'topology': now little discussed, but 40 years ago the subject of much debate as what O’Brien calls a pervasive model for understanding art. The 'irrational sound in-formation' embodied in the 'fuzzy transitions' of Reich's phasing compositions and the effect of spatial location on the perception of Young's music are just two of the topics that she addresses. As with Chapman, O’Brien is interrogating the 'usual-suspects' narrative as part of her agenda. ${ }^{17}$

There remain good reasons, of course, why we often think first of Reich and Glass here, rather than, notably, Young and Riley. O’Brien, for instance, suggests that we might still be underestimating the importance of technology for Reich as a trigger for new forms and ways of perceiving them - for all that we are aware, most obviously, of the role that the tape recorder played in the evolution of phasing. And

\footnotetext{
16 See David Chapman, 'Space, Collaboration, and Cultural Practice at Park Place Gallery and Film-makers’ Cinematheque, 1967-1968', paper presented at the Third International Conference on Minimalist Music(12-15 October 2011), Catholic University of Leuven, Belgium.

17 See Kerry O’Brien, ‘Early Steve Reich and Techno-Utopianism', paper presented at the Second International Conference on Minimalist Music(2-6 September 2009), University of Missouri-Kansas City, USA; and ‘Drifting and Phasing in Aspen 8', paper presented at the Third International Conference on Minimalist Music(12-15 October 2011), Catholic University of Leuven, Belgium.
} 
when seeking comparisons with Minimalist sculpture, the compositions of Reich and Glass offer clarity of conception, structural rigour and precision of utterance; they are solid musical objects capable of objectifying processes; and however much flexibility their scores may allow performers, we are never talking about anything that is meaningfully improvisational in the expressive sense that used to anger John Cage so much.

Young and Riley were, and remain, more concerned than Reich and Glass with the spiritual origins and purposes of their inspiration, and with the nature and nurture of inspiration itself, which any formal or technical application will only help make manifest, not seek to rival in significance. They have, accordingly, always been involved with an approach to improvisation that, rather than attempting to eliminate transformative labour as such, aspires to engage the guidance of forces higher than the musicians themselves in channelling the efforts of their imaginations (via the discipline of meditation, the practice of classical North Indian music and, at least in the past, the taking of mind-changing hallucinogens).

\section{First Case Study: Steve Reich}

But does Steve Reich's early music itself manifest all the attributes of the theory of minimalism suggested earlier? If one seeks the seeds of his subsequent involvement with harmonic direction, for instance - something important, if in many different ways, to many composers in the late twentieth century, including Young and Riley as well as Glass - one good place to find it is in Reich's already-mentioned work Four 
Organs (composed in 1970), with its dominant-eleventh chord, implying a V-I cadence, hung out to dry for the listener's inspection over some 15 minutes. What Ronald Woodley has called Reich's 'gradual realignment with certain branches of “mainstream” European music, a realignment achieved, however, through radicalization rather than compliant re-absorption' ${ }^{18}$ had, perhaps inevitably (and as I have suggested before), to begin with the purging power of rhythmic repetition on pitch materials themselves so reduced that little remained in them, for the listener, of their possible Western classical associations. Yet for all its radical rigour and harmonic reductiveness, Four Organs marks the beginning of Reich’s serious interest in harmonic motion: a story that I will take up again in the final section of this chapter. ${ }^{19}$

In some ways, however, the most telling Trojan Horse in the citadel of musical minimalism isn't actually a formalist or music-technical phenomenon at all, but the metaphorical interpretation that seems to spring irresistibly from Reich's tape composition, It's Gonna Rain, a work sometimes put forward as one of the basic building blocks of minimalism's aesthetic of purity and non-reference. If one seeks the seeds of an involvement with the 'comment, representation, or reference' said to be denied at minimalism's hard core, then the young black preacher's sermon that formed the material of that work, and its treatment in the work itself, are good places to find them.

\footnotetext{
18 Ronald Woodley, 'Steve Reich', in Brian Morton and Pamela Collins (eds.), Contemporary Composers (London, 1992), p. 768.

${ }^{19}$ For an example of recent scholarship on Reich in the early 1970s, but returning the story to issues of rhythm and metre, see Keith Potter, ““Drummed Out?” What Steve Reich did after Drumming’, Mitteilungen der Paul Sacher Stiftung, 24 (2011): pp. 35-41.
} 
John Pymm and I have recently been investigating the work’s source materials: first, reel-to-reel tape recordings made in June 1964 by Reich as the basis for It's Gonna Rain, now archived with the manuscript sources in the Steve Reich Collection at the Paul Sacher Stiftung, Basel, and digitally transferred by the Stiftung to CD; and second, 15 pages of handwritten sketches. The two tracks of audio material, lasting around 36 minutes, appear to be edited composites created by Reich himself from more extensive recordings. The gaps where the tape recorder is turned off and on make it impossible to calculate the overall timeframe of the recordings; but, by implication, the events all took place on a single day, which was almost certainly a Sunday, given the nature of the events in the square. The sketch materials consist of three pages transcribing sections of Brother Walter's 'street sermon' and a further twelve pages of compositional drafts based on extracts from this.

Reich has often said that he was pointed in the direction of the sonic and other attractions of Walter's open-air sermons by a film-maker friend, Robert Nelson, with whom he had previously collaborated and who was at that stage engaged in work for the subsequently lost film Thick Pucker (dating from 1965, as with It's Gonna Rain). The context for many of Reich's, and Nelson's, artistic endeavours at this period was that of a highly politicized avant-garde arts scene in San Francisco. One of the prominent players in this was the performance-art group, the San Francisco Mime Troupe, founded by R.G. Davis in 1959. This context offers support, Pymm and I 
argue, for ways of reading It's Gonna Rain that extend the symbolism of Noah and the Flood well beyond the boundaries at first glance offered by Reich's 'text' here. ${ }^{20}$

On the biographical level, too, one might add the connection that Reich himself makes, with Part 2 of the work in particular, to the divorce he was then going through. And as if this weren't already enough, Reich's output of this period has more recently been explicitly read in terms of African and race issues. Martin Scherzinger has sought to establish what he calls both 'local' and 'global' contexts for It's Gonna Rain, contradictory though these might be argued to be, as 'part of an attempt to elevate the role played by the African continent in shaping the evolution of Western music history': a bold project, dating from 2005, that has many ramifications for situating minimalism both within the cauldron of American culture in the 1960s and its legacy today. ${ }^{21}$

Sumanth Gopinath, who deals with Come Out as well as It's Gonna Rain, has argued - in his 2005 thesis and subsequent publications - that Reich's emerging concern with process-based composition was explored, among other contexts, in this manifestation of the Mime Troupe's response to New-Left political thinking, in general, and, in particular, to a countercultural stance that was able to incorporate

\footnotetext{
${ }^{20}$ For more on this recent research on It's Gonna Rain, see Keith Potter and John Pymm, 'It’s Gonna Rain: new light on its source materials', paper presented at the Third International Conference on Minimalist Music(12-15 October 2011), Catholic University of Leuven, Belgium; and Pymm’s chapter in the present volume.

${ }^{21}$ Martin Scherzinger, ‘Curious Intersections, Uncommon Magic: Steve Reich’s It’s Gonna Rain’, Current Musicology, 79/80 (2005): pp. 207-44; p. 237.
} 
current events such as the Watts race riots in Los Angeles in August $1965 .{ }^{22}$ Walter's reference to race riots, outside both the material that Reich selected for It's Gonna Rain and his transcription of it, surely lends further support to Gopinath's argument. Furthermore, Reich was involved in a kind of 'minstrel show', first developed by the Mime Troupe in late 1964 but only receiving its premiere some time after that of It's Gonna Rain, that appears to have been a kind of parody of the 'minstrel shows' that began in the nineteenth century. His own contribution to this was music to accompany a ten-minute film by Nelson, entitled Oh dem Watermelons, which featured at the end of the show's first act.

But as is well known, Reich himself has frequently suggested a more generally political, rather than specifically racial, dimension to the work, since he had 'recorded Brother Walter in 1964 ... shortly after the Cuban missile crisis', which occurred in October 1962. The thought that 'we might be going up in so much radioactive smoke' meant that 'with that hovering in the background and this preacher laying it down about the Flood and Noah, it really had a lot of resonance'. ${ }^{23}$ Evidence for this being the composer's intention at the time, as opposed to being some later gloss put upon the matter, is provided by a page of the composer's sketches for It's Gonna Rain. Here we find 'CUBA Si' written on the third stave: in capitals, save for

\footnotetext{
22 See Sumanth Gopinath, ““A Composer Looks East”: Steve Reich and discourse on non-Western music’, Glendora Review, 3/3-4 (2004): pp. 134-45; ‘The Problem of the Political in Steve Reich’s Come Out (1966)’, in Robert Adlington (ed.), Sound Commitments: avant-garde music and the sixties (Oxford, 2009), pp. 121-44; 'Reich in Blackface: Oh Dem Watermelons and Radical Minstrelsy in the 1960s', Journal of the Society for American Music, 5/2 (2011): pp.139-93; and Contraband Children: the politics of race and liberation in the music of Steve Reich, 1965-1966 (PhD diss., Yale University, 2005).

23 All these quotations are taken from Steve Reich, 'It's Gonna Rain (1965)', in Writings on Music, Hillier (ed.), p. 21.
} 
the final letter. This offers perhaps the most overt political comment connected to the work, with the direct citation of the first part of the slogan 'Cuba Si! Yanqui No!', the anti-USA cry of Cuban revolutionaries, apparently identifying Reich with a proCuban stance. The Cuban missile crisis had created a deep and pervasive unease that, as the composer himself puts it, 'nuclear disaster was a finger on the button away'. ${ }^{24}$ Even more than two years later, this gave the story of Noah and the Flood a fresh, and urgent, dimension, enhanced by repetition that in itself is characteristic of this Evangelical style of preaching. The words of It's Gonna Rain thus in turn offer its audience a metaphor for impending nuclear holocaust.

Then there is the religious dimension itself, although it would seem that the composer's decision is unlikely to have been specifically religious: Reich has been clear that he did not take his Jewish heritage at all seriously until the mid 1970s, and that is another story. Yet these 36 minutes of edited tape provide something of a religious marketplace: Walter and his fellow Pentecostals; the vegetarian who turns out to be a Seventh-Day Adventist; a woman called Naomi, who expounds a mixture of homespun common-sense philosophy and quasi-supremacist views; and the moralizing of the winos as to what constitutes acceptable behaviour, culminating in the deeply significant comment, 'when you steal from a wino, you steal blood', which becomes entangled with Walter's message of forgiveness. In some vicarious way, Walter's voice can be said to speak for this religious diversity.

The sonic qualities of speech seem, however, to have been pre-eminent for Reich. Heightened speech is inevitably more sonically vivid than ordinary speech, and

\footnotetext{
24 Steve Reich, quoted in Potter, Four Musical Minimalists, p. 167.
} 
more likely to sustain interest when subjected to repetition. Examples abound in these field recordings: the wino we heard at the beginning of this presentation ('But I was never good enough to be a musician, big time', or 'Wine, jazz and chess: at my particular stage of the game, that's all I'm interested in') might, for instance, have worked as a speech sample, though the fact that Walter is to be heard preaching in the background would have presented problems if using this extract in a composition. Or Naomi, the only woman on these tapes (perhaps represented by 'I love God: you want to make something out of it?'). Or even the other (singing) preacher, whose contributions would be already too musicalized, perhaps, to allow successful manipulation; though other composers have, of course, sampled melodies. 'On the verge of singing' is, tellingly, what Reich himself stresses as especially potent about Walter's speech. ${ }^{25}$ The content and sonic dimensions of some of the other material on these tapes would, however, ultimately prove less suggestive and less amenable to repetition than the rantings of Brother Walter in full flood (as it were).

Pymm and I would thus not wish to argue that a race-based, a nuclearholocaust or a religious interpretation of It's Gonna Rain is wrong; nor, incidentally, that only one of these can be embraced at one time. Rather, it seems to us that these are merely three of many possible readings of the work, all of which are made allowable by Reich's success in creating in his listeners an 'emotional feeling ... that you're going through the cataclysm, you're experiencing what it's like to have everything dissolve' via a 'process ... [that] inexorably works itself out'. We would, accordingly, be inclined to draw attention here to those sorts of interpretations that emphasize apparently less specific, arguably more musical, meanings behind It's

\footnotetext{
25 Reich, ‘It’s Gonna Rain’, p. 19.
} 
Gonna Rain. Such readings seem in direct accordance both with Reich’s desire, in composing this work, to 'keep the original emotional power that speech has while intensifying its melody and meaning through repetition and rhythm', and with his apparent concern, in selecting material for it, to find the best route not to 'setting a text ... [but to] setting a human being' ${ }^{26}$

If Reich's early music is not, after all, the most unimpeachably radical 'take' on minimalism in music as a reflection of Minimalist concerns in visual art, then who, or what, might represent an even more robustly radical stance?

\section{Second Case Study: La Monte Young v. Tony Conrad}

Two different ways of charting the significance of La Monte Young (b. 1935) now seem to have crystallized, as summarized in 2008 by Branden Joseph. ${ }^{27}$ On the one hand, there's the interpretation that, taking off from Composition 1960 \#7, uses the pure, perfect fifth of that work's B and F\# as the link between the long-held pitches of Trio for Strings (1958) and the drone minimalism that Young would develop from 1962 onwards in the work of The Theatre of Eternal Music, in the Dream House installations, in the massive solo piano improvisation, The Well-Tuned Piano (1964 onwards) and much else besides. Young's search for an 'eternal music' fusing mystical and acoustic concerns in order to facilitate new psychic states - via immersion in the harmonic series, prolonged exposure to loud drones and experiences

\footnotetext{
${ }^{26}$ All the quotations in this paragraph are taken from Reich, 'It’s Gonna Rain’, pp. 20-21.

27 See Branden W. Joseph, Beyond the Dream Syndicate: Tony Conrad and the arts after Cage (New York, 2008).
} 
with LSD, marijuana and peyote - can be traced with special focus from Composition 1960 \#7, though it can also be tracked further back to his instrumental works of the 1950s. His exploration of non-Western musics, his pioneering work with sustained sounds, his saxophone playing that emulated but also extended the approach then being developed by John Coltrane, as well as his shorter-lived interest in performance art, were additionally reflected in Terry Riley's compositions and other musical activities of the early 1960s.

On the other hand, there's the interpretation that, taking off from Young's Composition $1960 \# 10$, uses that straight line (and its own followers) as the link to a more obviously 'conceptual' future. Joseph argues that it was Tony Conrad (b. 1940) - improvising violinist, mathematician, film-maker and one-time member of The Theatre of Eternal Music - who would develop the conceptual proposition behind Young's straight line from then onwards by questioning notions of both authorship and object, ignoring the conventional boundaries between arts and, even when he was making musical performances, conceiving and executing them against the grain of all 'received' modernist, and indeed probably all artistic, institutions. The category of institutions that Conrad dismissed ultimately includes The Theatre of Eternal Music itself, once it proved (in Conrad's interpretation) merely a vehicle for Young's own ego and ideas.

This period around 1960 is at once the most-commented upon and, perhaps, the least understood in Young's output; it certainly sometimes seems an aberration in a career otherwise spent pursuing drones and other more purely musical phenomena with an obsession unrivalled by any other composer. Jeremy Grimshaw, whose 2005 
thesis and 2011 book represent landmarks in Young scholarship, characterizes the years 1959 to 1961 as a time in which the works 'seem bizarre and intractable conceptual disruptions of Young's otherwise smooth and contiguous evolutionary curve'. ${ }^{28}$ In 2000, I wrote that, for Young after 1961, 'The titillation of Fluxus was to be avoided in favour of a fresh look at the potential of boredom'; and then, quoting Flynt's seminal 'Mutations of the Vanguard' essay, that Young 'prolonged monotony in art - the position which would later be called minimalism'. ${ }^{29}$

Yet Grimshaw supplies a highly perceptive twist of his own to the first of the above interpretations of Composition 1960 \#7 and Composition 1960 \#10. Having argued that the New York performances of Young’s Poem for Chairs, Tables, Benches, Etc. (or other sound sources) (1960) had primed a new audience, who included John Cage and Andy Warhol, for the New York premiere of Trio for Strings in 1962 to hear this earlier 'more Webern-than-Webern' serial composition as in reality 'a radical quasi-conceptual work', he then goes on to suggest that Poem also marked a further development in what would become a central issue of Young's mature oeuvre: the spatialization of sound. In Poem, as in Vision [his 1959 composition for 'unconventional sounds articulated on conventional instruments'], the positionality of sounds within the performance venue conveys a sense of space that correlates in some way

\footnotetext{
28 Jeremy Grimshaw, Music of a 'More Exalted Sphere': compositional practice, biography, and cosmology in the music of La Monte Young (PhD diss., University of Rochester, 2005), p.97; see also Jeremy Grimshaw, Draw a Straight Line and Follow It: the music and mysticism of La Monte Young (New York, 2011). The present chapter was written before the latter volume was published, and the controversy that it raised will not be discussed here. Readers should, however, note this important contribution to minimalist scholarship.

${ }^{29}$ Potter, Four Musical Minimalists, p. 55; see also Henry A. Flynt, Jr., 'Mutations of the Vanguard’, in Gino di Maggio (ed.), Ubi Fluxus Ibi Motus: 1990-1962 (Milan, 1990), p. 105.
} 
with reconfiguration, in the sonic plane, of time as space (with the often long silences between sound events analogous to distances between physicalobjects). The kinds of sounds suggested in Poem, however, offer the first hints of a new sonic/spatialmetaphor, one that would come to dominate the acoustical structures of Young's later compositions. In an unpublished note on Poem from 1989, Young stated that his attraction to the scrannel sounds of furniture dragged along floors as well as the variety of other, similarly unconventional friction-based sounds he explored during this time stemmed from the highly complex overtone structures such sounds created. Young directly linked the harmonic complexity of these sounds to his increasing penchant for listening to them for very long stretches; the longer one listened, he discovered, the more one could discern overtone structures. He likewise connected complex harmonics and extended durations to the idea of getting 'inside' a sound; in other words, when the time frame is extended, Young suggested, it grants the listener 'room' to explore from within the sonic space articulated by complex harmonics. The later installation works, then, simply literalize the spatial metaphor first suggested in the sonorous screeches of Poem: whereas the earlier work presented a literally spatial element - sounds coming from various directions alongside the spatial metaphor of overtone complexity, Young's installations combine these two strands such that physicalpositionality within the venue facilitates the sonic exploration of the sound environment's intricate harmonic structures. ${ }^{30}$

That all seems to me very appropriate, and nicely connects up certain aspects of Young's 'second period' while still maintaining the view that, taken as a whole, the period of the text compositions is somewhat anomalous in terms of his overall development. As I’ve suggested, most commentators, myself included, agree that the years 1959 to 1961 represent a departure, indeed a rupture, of some magnitude in

\footnotetext{
${ }^{30}$ Grimshaw, Music of a 'More Exalted Sphere', pp. 98-9. Dictionaries variously define 'scrannel' as 'thin', 'harsh' and 'unmusical': 'scrannel sounds' here are the aural consequences of this score's instruction to drag 'ordinary, readily available furniture ... across an engaging floor surface'.
} 
Young's development. But all this is to ignore the claims of what has come to be known as 'minor history'.

The notion of 'minor history' emanates in part from the theoretical work of Gilles Deleuze. But it also seems to emerge from The Poetics Project, instigated by the American artists Mike Kelley and Tony Oursler as a means of critiquing how meanings are constructed and deployed: both in the development of art practice itself, and in the development of the history and institutions that reflect that art practice as well as define what it is for a wider audience. It is no surprise that such arguments revolve around crossover media. And the big issues here, of course, swirl around authorship and interpretation.

Working with this notion of 'minor history', Joseph - an art historian - has posited an alternative interpretation of Young's evolution: an interpretation that develops out of the schism within The Theatre of Eternal Music that has long been embodied in the feud between Young and Marian Zazeela, on one side, and Conrad and John Cale, on the other. In Beyond the Dream Syndicate: Tony Conrad and the arts after Cage (the Dream Syndicate was one of the alternative titles given to The Theatre of Eternal Music), Joseph designs his argument not so much to support a case for continuity as opposed to discontinuity in Young's output, but rather to make the case for what he calls a 'minor history' that can then be used to support Conrad's cause against that of Young.

In grand cultural-theoretic terms, these issues are the key unlocking shedloads of debate, often starting with Roland Barthes' notion of the 'Death of the 
Author'. Barthes' infamous text challenged single readings, not single writings, we should remind ourselves. But for present purposes it remains tempting to point out that this text appeared in English in 1967, not all that long after Conrad says that his arguments with Young began, before it did so in French. ${ }^{31}$ Joseph does not inform us when Conrad was first aware of Barthes' work, but he does report that more recent scholarship by Liz Kotz suggests that the Death of the Author 'was likely a reimportation of the idea into literature and art from the context of contemporary music'. ${ }^{32}$ This only makes the whole subject even more intriguing for present purposes; some minimalist scholar should really run with it properly at some point. For musicians, of course, the debate soon starts to revolve around the matter of whether improvisation should take aesthetic priority over composition; and, if composition is not to be rejected outright, then how composition and improvisation may interact. Text scores, as well as graphic scores, perhaps especially when inviting multi-disciplinary performance, are prime sites for these debates; which is why Joseph, with the brilliant and feisty Conrad's assistance, can already make so much of it all.

So, then, just as on one side we have a perfect fifth leading inexorably to musical minimalism as we generally know it, on the other side we have a straight line, real or conceptual, as the link to a more obviously 'conceptual' future. Or, to put it a

\footnotetext{
31 An English-language version appeared in the American journal Aspen, 5-6 (1967): interestingly, the same journal on which some of Kerry O’Brien's research is based (see n. 17 above). A French version was published only the following year, in Mantea, 5 (1968). For a more accessible English publication of this seminal text, see Roland Barthes, The Rustle of Language, trans. Richard Howard (Oxford, 1986), pp. 49-55.

32 Joseph, Beyond the Dream Syndicate, p. 80; and Liz Kotz, 'Post-Cagean Aesthetics and the “Event” Score', October, 95 (2001): p. 59, including n. 10.
} 
second way, Joseph prefers to see Compositions 1960 as 'an almost epistemological enquiry' that, among other things, 'amount[s] to a multifaceted probing into various tenets of Cage's work, not all at once and in its [entirety], but particularly, part by part. Each of Young's scores isolates, emphasizes, questions, and usually demonstrably attempts to surpass one or another aspect of Cage's position.'33

A single one of Joseph's several examples will have to suffice here: Composition 1960 \#15 (the little whirlpools) and Piano Piece for David Tudor \#3 (the grasshoppers) are, he writes, 'bids to outdo Cage in the realm of indeterminacy, not only by removing any explicit directive to the performer, but by confounding any implicit one, as well'. The grasshoppers composition, in addition, 'foregrounds' the Oriental culture that Cage also confronted. However, Joseph also exposes, and celebrates, the diversity of Compositions 1960 as well: 'When taken as a collection', he writes, 'rather than selected for continuity with earlier and later developments, Young's word pieces point in diverse, even opposing or contradictory directions, the silence and indeterminacy of Composition 1960 \#5 [the butterfly], for example, being largely at odds with the auditory control embodied in Composition 1960 \#7 [the perfect fifth]'. ${ }^{34}$ Between them, Grimshaw and Joseph have made significant contributions to the study of Young and Conrad, and to the multi-disciplined, sometimes contradictory areas of creative and cultural work that have emerged from the concerns of these two multi-faceted creators in the 1960s.

\footnotetext{
33 Joseph, Beyond the Dream Syndicate, p. 93.

34 All the quotations in this paragraph are taken from Joseph, Beyond the Dream Syndicate, pp. 93 and 95.
} 


\section{(Post?)minimalis m as Postmodernism?}

By the year 1976 - twelve years after Terry Riley’s In C, eighteen years after La Monte Young's Trio for Strings - musical minimalism had clearly moved on. Readers of this volume will probably not need the evidence in detail: everything from the premiere performances, in that year, of Steve Reich's Music for 18 Musicians, and Robert Wilson and Philip Glass's Einstein on the Beach (both 1974-6), to the emergence of John Adams, who incorporated quotation and reference into a patternbased minimalism that soon took off on quite different paths from those of his compatriots a decade older than he; and, of course, also a host of contemporary European as well as other American developments. It is uncanny, on the face of it, that so many composers moved into minimalism, or came to achieve a mature expression of it, around 1976 or at any rate 1977: Louis Andriessen, Henryk Górecki, Michael Nyman, Arvo Pärt, John Tavener, Walter Zimmermann - the list goes on and on.

What exactly was the nature of this spirit, of this change? And why did it happen when it did? There is, of course, a whole raft of possible reasons to be found in the variety of reception histories of musical minimalism that might be traced: in an examination of the influences that the early minimalists had on subsequent endeavours, their own included; in the cultural and musical politics of which David Lang has spoken so eloquently; ${ }^{35}$ and so on. The issues of conception, realization and reception that surround Reich's It's Gonna Rain are part of the evidence that this

\footnotetext{
35 See Potter, Four Musical Minimalists, p. 20.
} 
change can already be detected even in early hardcore minimalism's aesthetic intentions, technical considerations and effects on the listener.

Some would argue that musical minimalism's greatest contribution is to have pointed the way towards the erosion of cultural as well as purely musical barriers, enabling composers to explore a pluralism freed from the shackles of earlier certainties. While this is perhaps a curious situation in view of the supposed purity of Minimalist art's, and minimalist music's, original manifestations, it does begin to explain both how and why later musical minimalism became one of the most notable developments in late twentieth-century musical culture. We should remember the first of the late K. Robert Schwarz's defining dicta of minimalism: that 'To its supporters, its directness and accessibility restores the severed link between composer and audience’. ${ }^{36}$ But we should also recall John Richardson’s shrewd observation in 1999 on the difference between the fate of minimalist music in 'high culture' and that of Minimalist art. 'It is no coincidence', he writes,

\footnotetext{
that minimal art entered the canon with relatively little resistance, while remaining the almostexclusive cultural property of a small group of initiates, whereas minimal music largely failed to achieve canonical status yet spread far beyond the pale of the musical intelligentsia. Judging from the critical reception of musical minimalis m, it was precisely its success with a broader public that made its incorporation into the canon an impossibility. ${ }^{37}$
}

Kyle Gann wrote in 1998 that

\footnotetext{
${ }^{36}$ K. Robert Schwarz, Minimalists (London, 1996), p. 8.

37 John Richardson, Singing Archaeology: Philip Glass’s Akhnaten (Hanover CT, 1999), p. 28.
} 
By the time minimalism emerged as a public phenomenon in 1973, it was squeaky clean and spruced up for company. And as the audience for minimalis m grew, it became known as a music of pretty harmonies, hard-edged melodies, and motoric rhythms, made by the tightly knit ensembles of two highly visible figures, Steve Reich and Philip Glass. ${ }^{38}$

Harmonic language is but one aspect, of course, of the argument here concerning how what might be regarded as minimalism’s ‘diaspora’ has fed into, and meshed with, broader currents both musical and cultural. It is, nevertheless, a potent one for all this music's listeners, and to select it as the focus for my final ruminations here seems entirely appropriate. Once again, my example will be Reich.

'Pretty harmonies' may have seduced some commentators on the music of composers such as Reich, Glass and many others dating from the mid-1970s onwards into suggesting that we can listen to, and dissect, such scores as though they were much like other tonal music of periods before the motor of rhythmic repetition so evidently drove the vehicles of early, hardcore minimalism off the road. Jonathan Bernard, who has himself undertaken some shrewd analysis of minimalist scores, warned, in 1995, of the dangers of assuming that

The so-called 'return to harmony' or even 'return to tonality', much remarked upon by critics, is (at least in the case of Reich and Adams) really an appropriation of harmony for purposes that are essentially new and not yet at all well understood. To assume that composers, by retrieving such superficially familiar sonorities as triads and major-minor seventh chords, have

\footnotetext{
38 Kyle Gann, ‘Minimalism Isn’t Pretty’, Village Voice, 153/17 (28 April 1998): p. 141; reprinted in Gann, Music Downtown: articles from The Village Voice (Berkeley, 2006), p. 203.
} 
also taken on, whether intending to or not, the hierarchical nature of common-practice tonality (if not its specific structures) may be assuming far too much. ${ }^{39}$

That is advice we should take seriously, both when considering, say, the early minimalism of Reich and Glass, and what they have composed since 1976.

Bernard's later distinction, made in 2003, between what he calls the third and fourth 'stages' that he identifies in 'the story of what happened after [the] initial establishment of minimalism' makes the point even more clearly. In 'Stage 3', 'pieces began sounding more explicitly "harmonic", that is, chordally oriented, though not, at this point, necessarily tonal in any sense'. In 'Stage 4', 'harmony of an ever more tonal (or neotonal, or quasi-tonal) aspect assumed primary control', leaving minimalist devices 'pushed into the background, where they became stylistic objects' ${ }^{40}$

His warning about the need to understand how what some would term neotonal harmony actually functions (the word seems particularly apposite), in the later music of composers such as Reich and Adams, might make broader sense, as well, in the context of efforts to distinguish new ways of using 'old' materials from any simple return to 'old' ways of using them. Hal Foster's now venerable distinction

\footnotetext{
39 Jonathan W. Bernard, 'Theory, Analysis, and the “Problem” of Minimal Music', in Elisabeth West Marvin and Richard Hermann (eds.), Concert Music, Rock, and Jazz since 1945: essays and analytical studies (Rochester NY, 1995), p. 284.

40 Jonathan W. Bernard, 'Minimalism, Postminimalism, and the Resurgence of Tonality in Recent American Music', American Music, 21/1 (2003): p. 114.
} 
between 'a postmodernism of resistance' and a 'postmodernism of reaction' ${ }^{41}$ is but one way of getting such an argument going along broader lines that would quickly take us away from issues of harmonic language per se. For some, these composers' later accommodation into the contemporary-musical mainstream is understood simply and entirely in terms of backsliding. For those of us who wish to penetrate further into the question of whether such music can find new uses for the motor of rhythmic repetition in what may be only superficially familiar contexts, what sorts of analytical tools can we bring to our aid in understanding the significance of dividing the minimalist map into two, with a fairly firm line drawn when we reach 1976 ?

Reich’s Music for Mallet Instruments, Voices and Organ (1973) begins, via its oscillation of simple two-chord sequences, to develop a new approach to harmony, starting at least to imply the sense of increased directionality that does a good deal to characterize much minimalist music of the last forty years. Such a putative approach to harmonic direction is certainly ambiguous, evasive even. Yet this is, of course, precisely what makes listening to it - and grappling with how to analyze it - all the more interesting. A lot of the minimalist music composed around 1976 has, I've always felt, an 'on-the-edge' quality to it that is especially enticing. I have elsewhere suggested that the point reached here in terms of harmonic direction was not one that could now be halted, however exciting this 'on-the-edgeness' itself might be. ${ }^{42}$ The hair-shirted advocates of hardcore minimalism were still right to feel dismayed by Mallet when it first appeared; for by their yardstick of musical value, the work had certainly taken an important step in a different direction.

\footnotetext{
41 See Hal Foster's introductory essay in Foster (ed.), Postmodern Culture (London and Sydney, 1985), pp. i-xii.

42 See, for example, Potter, Four Musical Minimalists, p. 246.
} 
Relationships between chord and pulse, tentative melody, sensory textures and, most of all, the dastardly double-act of speed-warp and incipient harmonic directionality also determine the even more radical stance taken by Reich's Music for 18 Musicians. This is well demonstrated by the arrival of Section VI of this work's eleven sections (each based, though sometimes extremely loosely, it has to be said, on one of the chords in the richly ambiguous chord progression now famously outlined in the work's first five minutes). I have called Sections VI-VII, with their introduction of the continuous rattle of maracas, 18 Musicians' 'scherzo', before the more complex machinations of the 'finale' begin in Section IX. I have also previously noted the selfquotation, in the preceding Section V, of the composer's own Violin Phase; in the context of '1976 and all that', it is tempting to stress this still early American example of musical referencing. ${ }^{43}$

Robert Fink - who imaginatively sees these maracas as a 'coded reference' to those keeping the pulse for the organs of the composition Four Organs (thus adding, I would argue, to the evidence provided above for early minimalism as a seedbed for later developments) - described this in 2005 as 'a moment of recombinant teleology'. ${ }^{44}$ Essentially a more sophisticated approach to establishing the precise nature of the directional ambiguity to which I have been referring, this 'recombinant teleology' offers a subtle way of pursuing the balance and relationship between the apparently contradictory concerns of directionality and stasis, in which the listener's

\footnotetext{
${ }^{43}$ See Potter, Four Musical Minimalists, pp. 242 and 241 respectively.

${ }^{44}$ Fink, Repeating Ourselves, pp. 54-5; his discussion of 'recombinant teleology' in Music for 18 Musicians is on pp. $47-55$.
} 
conflicting impressions of the speed of different layers of the music play an important part.

\section{Ex. 1.1 Steve Reich, Music for 18 Musicians, transition from Section V to Section}

VI

Example 1.1 shows the main features of the move from Section $\mathrm{V}$ to Section VI. Fink makes more than does my own published analys is of Music for 18 Musicians of the C sharp in the bass of Section V (a departure from the 'official' chord of that section) and its dominant function, in preparation for the F sharp of the ensuing Section VI. For him, on his way to 'reading disco as minimalism', Reich's dominantto-tonic move here 'manipulates[s] musical parameters to create [an] overt moment of teleological drama'; a climax implying 'an all-encompassing teleology that the music itself does not actually provide'. ${ }^{45}$

Maybe Reich's charge of musical energy here is sufficiently potent not to need the underlining that Fink provides in his accompanying analysis of what he calls 'musical erotics' in Donna Summer and Giorgio Moroder's 'Love to Love You Baby', with its simulated sounds of sexual intercourse. Summer and Moroder's infamous disco hit, which Fink calls 'arguably the first extended dance remix in disco history', was released in its full 17-minute version in 1975 and reached its peak in the charts in February 1976, just two months before Music for 18 Musicians was

\footnotetext{
45 Ibid., pp. 47, 56 and 55, respectively.
} 
premiered on 24 April in New York in its completed version. ${ }^{46}$ It is especially strange, though, in this context, that Fink doesn't make more of another engine of thrustful energy, new in minimalist music when Music for 18 Musicians was first heard: the pulsing notes played or sung, for the length of a breath, mainly by voices and clarinets, rising and falling from silence to forte and back to silence, each swelling slightly staggered between the instruments. 'Gradually washing up like waves', the composer describes the effect in his programme note to the work. In the context, also, of the gendered explanations that Fink additionally offers for his examples (and tonal motion has, as we know, been compared by others to the sex act), there is surely only one interpretation for these wave-like motions: female multiple orgasms. Minimalists - mostly if not always male, and especially the so-called English experimentalists (exclusively male) - had previously been wary even of the simple crescendo and diminuendo, let alone anything more clearly sexually suggestive like this. (As the title of the 1971 West-End comedy had it, 'No sex, please, we're British'.)

Despite the innuendo, I have now strayed into the challenges for musical analysis that are posed by minimalism, which is for others in this volume to take further. ${ }^{47}$ In concluding my ruminations on 'mapping' early minimalism, then, I should simply report that the efforts that I made more than ten years ago to find methods of analysis that both respected what I understood of the intentions of composers such as Reich and Glass in the 1960s and 1970s, and reflected as precisely

\footnotetext{
46 Ibid., p. 26; his discussion of 'recombinant teleology' in 'Love to Love You Baby' is on pp. 55-61.

47 See, in particular, Tristian Evans’s chapter, ‘Analy zing Minimalist and Postminimalist Music: an overview of methodologies'.
} 
as possible the way in which I was listening to their music of this time, drew me to two conclusions. First, that harmonic motion was indeed crucial to the changes wrought in the music of Reich, Glass - and surely many others, too - around 1976. Second, that such harmonic motion was increasingly latent in the music that these two composers had been writing for the ten years or so prior to that time. The more that I felt confirmed in these views on the evolution of musical minimalism, the more valid seemed an analytical approach predicated on attempting to unpick how that harmony unravelled and, in particular, how its listeners would perceive it and deal with it. The search goes on ... 